\title{
First isolation of Dicrocoelium dendriticum among cattle in some Northern Algerian slaughterhouses
}

\author{
Linda Chougar, Kh. Harhoura and M. Aissi \\ Animal Health and Productions Laboratory, High National Veterinary School, B.P.228, Oued Samar, Algiers, Algeria. \\ Corresponding author: Linda Chougar, e-mail: linda.chougar@gmail.com \\ Co-authors: KH: harhourakhaled@yahoo.fr, MA: aissimiriem@yahoo.fr \\ Received: 30-12-2018, Accepted: 06-06-2019, Published online: 16-07-2019
}

doi: 10.14202/vetworld.2019.1039-1045 How to cite this article: Chougar L, Harhoura K, Aissi M (2019) First isolation of Dicrocoelium dendriticum among cattle in some Northern Algerian slaughterhouses, Veterinary World, 12(7): 1039-1045.

\begin{abstract}
Background and Aim: Dicrocoelium dendriticum or small liver fluke often causes unnoticed clinical manifestations in cattle. For a live animal, its diagnosis is mainly based on the detection of eggs by coproscopic examination. The objective of this study was to determine the presence or absence of Dicrocoelium spp. never previously reported in the study area but also to establish its prevalence, as well as an association between dicrocoeliasis and sex, age and season of the year, and histological characteristics.

Materials and Methods: The study was carried out in slaughterhouses of three districts (Bouira, Tizi-Ouzou, and Bejaia) from January 2017 to December 2017. To this end, of 4053 cattle, representing more than $10 \%$ of the total number of animals slaughtered, stool and bile samples were collected and a liver inspection was carried out to investigate lesions of distomial cholangitis. They were processed for histological analysis. The specimens were morphologically identified according to the orientation of the testicles, the length and width of the body, and the level of the maximum width of the body.

Results: The total prevalence of dicrocoeliasis obtained of the 4053 cattle inspected is $0.52 \%$ with a prevalence of $0.66 \%$ in Tizi-Ouzou, $0.54 \%$ in Bouira, and $0.27 \%$ in Bejaia. About $0.52 \%$ of livers had distomial cholangitis $(21$ of the 4053 livers examined had adult $D$. dendriticum and $15 \%$ had non-distomial cholangitis. About $0.25 \%$ of cattle had $D$. dendriticum eggs in the stool versus $0.52 \%$ of cattle had parasite eggs in the bile. Statistical analysis revealed no significant association between dicrocoeliasis infection and the season of the year $(p>0.05)$. However, a significant association was found between dicrocoeliasis infection and sex and age of the animal $(\mathrm{p}<0.05)$; females and older animals are more likely to have dicrocoeliasis. Histological analysis of the fluke revealed an anterior positioning of the testicles with a slightly oblique tandem orientation, an average body length of $3.69 \mathrm{~mm}$ and an average body width of $1 \mathrm{~mm}$. The maximum body width level is either in the middle of the fluke body or in the rear position.
\end{abstract}

Conclusion: The histological study confirms that the collected fluke is $D$. dendriticum. Thus, this work reveals for the $1^{\text {st }}$ time in Algeria the presence of $D$. dendriticum in three districts (Bouira, Tizi-Ouzou, and Bejaia). The results indicate that many cattle farms in the North Central Province of Algeria are infested with D. dendriticum.

Keywords: bile, cattle, dicrocoeliasis, Dicrocoelium dendriticum, liver, stools.

\section{Introduction}

Dicrocoelium dendriticum, which causes liver fluke disease in ruminants and is of zoonotic and economic importance. It is prevalent in many regions of the world [1-3]. Although it has been identified in America, Asia, North Africa, and Europe, dicrocoeliasis is a little-known parasitic disease [4]. D. dendriticum lives in the adult stage, in the bile ducts, canaliculus, and gallbladder of its hosts (cow, sheep, goat, and pig) [5-7]. Humans can become accidentally infected by swallowing ants on vegetation or on various fruits. Children are, therefore, affected more frequently [8]. From an economic point of view, $D$. dendriticum causes a lot of damage to the livestock industry every year [9].

Copyright: Chougar, et al. Open Access. This article is distributed under the terms of the Creative Commons Attribution 4.0 International License (http://creativecommons.org/licenses/ by/4.0/), which permits unrestricted use, distribution, and reproduction in any medium, provided you give appropriate credit to the original author(s) and the source, provide a link to the Creative Commons license, and indicate if changes were made. The Creative Commons Public Domain Dedication waiver (http:// creativecommons.org/publicdomain/zero/1.0/) applies to the data made available in this article, unless otherwise stated.
This parasite, which lives in the liver of its definitive host, involves a gastropod snail as the first intermediate host and an ant as the second intermediate host in its life cycle. Sporocysts and cercariae, which are larval stages of the parasite, live in the hepatopancreas of terrestrial snails, metacercariae are also larval stages, in the abdomen and brain of ants (second intermediate host). The parasite has a slight specificity of the definitive host, with a preference for ruminants, which can be considered as the true host of origin, including mainly sheep and goats, and secondarily large ruminants such as cattle [10]. The number of reports on dicrocoeliasis is increasing in many countries due to the expansion of dry habitats and parasites that have become resistant to antihelminthics [11].

In Algeria, only one study reported the presence of dicrocoeliasis in the Mitidja's area (Northern Algeria) with a prevalence in cattle of $0.07 \%$ and $0.86 \%$ corresponding to fluke and eggs positive cases [12]. However, no data on dicrocoeliasis have been reported in Tizi-Ouzou, Bouira, and Béjaia (Kabylie region). 
This study aimed to investigate the presence and prevalence of dicrocoeliasis among cattle with histological characteristics in several slaughterhouses from three districts in Northern Algeria and to detect factors associated with $D$. dendriticum infection.

\section{Materials and Methods}

\section{Ethical approval}

The study was not conducted on live animals, but only on animals slaughtered at approved slaughterhouses as a routine slaughtering practice.

\section{Study area}

The studies were carried out in several slaughterhouses from three districts in Northern Algeria: TiziOuzou, Bouira, and Bejaia (Kabylie region). This area is characterized by the Mediterranean climate and is divided by two geographical barriers, the Tell and the Sahara Atlas. Northern Algeria is characterized by a cold winter and a warm summer with heavy rainfall (Figure-1).

\section{Identification of the animals}

Samples were collected daily from January 2017 to December 2017. The selection of slaughterhouses per day was randomly chosen. An investigation report form was completed for each sampled cattle, indicating the origin of the animal, which was determined from information provided by the farmers, the sampling season, sex, and age of the animal, which was determined by dentition and confirmed by the slaughter orientation form signed by the veterinarian. All sampled cattle were categorized into three age groups: $<2$ years, $2-4$ years, and $>4$ years and finally the appearance of liver during the inspection.

\section{Collected samples}

Stool sample

After evisceration of the carcass, $150 \mathrm{~g}$ of feces samples were collected from the rectum and placed in a box, then stored in the refrigerator at $+4^{\circ} \mathrm{C}$ until analyzed.

\section{Bile sample}

Bile was collected by puncturing the gallbladder with a $5 \mathrm{cc}$ syringe. The bile thus collected was stored in the refrigerator at $+4^{\circ} \mathrm{C}$ until it was analyzed.

\section{Flukes sample}

The specimens of Dicrocoelium were collected after necrotic inspection of the livers of slaughtered cattle at various slaughterhouses in the North Central Province of Algeria. The specimens were morphologically identified based on the descriptions made by Yamaguti [13], Hinaidy [14], Taira et al. [15], Otranto et al. [16], and Bourgat et al. [17].

\section{Diagnostic methods}

\section{Liver inspection at the slaughterhouse}

The inspection of the livers took place after total evisceration and cutting of the carcass. It was carried

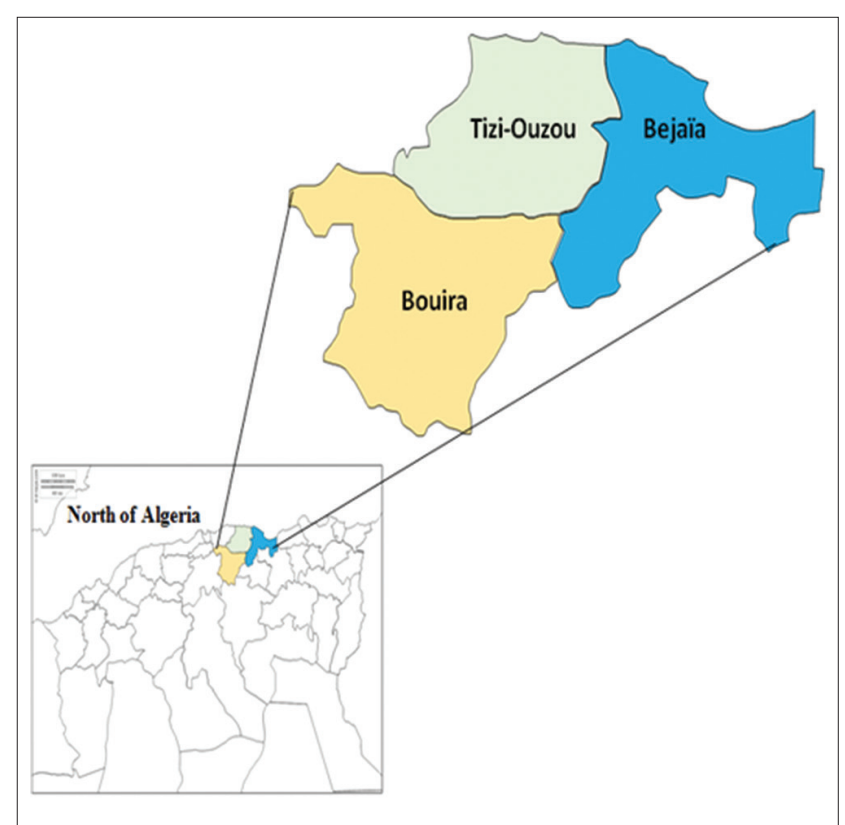

Figure-1: Map of the study area (Bouira, Tizi-Ouzou, and Béjaia). [Source: https://d-maps.com/index.php?lang=fr].

out through two mandatory regulatory incisions. The first was broad and superficial located at the level of the large bile ducts at the base of the pallet and the second was short and deep perpendicularly located at the level of the caudate lobe.

\section{Stool analysis (coprological analysis)}

Coprological analysis was performed by two methods, namely, the sedimentation technique using the Dinnik and Dinnik sedimentation method [18] and the flotation technique based on the Teuscher method [19].

\section{Bile analysis}

The bile contained in the syringes was transferred into conical tubes. The tubes were centrifuged (at $5000 \mathrm{rpm}$ for $1 \mathrm{~min}$ ) for $10 \mathrm{~min}$. About $2 \mathrm{ml}$ of the biliary pellet obtained were sucked up with a Pasteur pipette and placed on a slide and covered with a slide. The sample was observed under an optical microscope at $100 \times$ and $400 \times$ to determine the presence of D. dendriticum eggs.

\section{Flukes preparation for histology}

After collecting the parasites, the flukes were washed with phosphate-buffered saline to remove all traces of bile and were fixed at $10 \%$ formalin for at least $24 \mathrm{~h}$ by immersing them in 10 times their volume. At the end of this fixation, the histological treatment and coating of the paraffin were carried out using conventional techniques. The sections from 3-4 $\mu \mathrm{m}$ were obtained by microtome of each block and stained with hematoxylin and eosin according to standard histological protocols. The sections were examined and measured with a micrometer.

\section{Statistical analysis}

Data analysis was performed using IBM SPSS Statistics 22.0 software. Tests used the Pearson 
Chi-square test. A significant association between animal positivity to dicrocoeliasis and the sex, age, and season of the year was determined if $\mathrm{p}<0.05$.

\section{Results}

The results showed that the total prevalence of dicrocoeliasis was $0.52 \%$, which represents 21 positive cattle of 4053. The parasitized livers presented lesions (Table-1), parasite (Figure-2a and b), and parasite eggs in bile $(0.52 \%)$ (Figure-3a). However, only $10(0.25 \%)$ of affected cattle revealed the presence of $D$. dendriticum eggs in coprology (Figure-3b and Table-1). The study included 1658 cattle from Tizi-Ouzou region. Among them, $11(0.66 \%)$ were found positive for dicrocoeliasis with the presence of the parasite and eggs. In Bouira Province, of 1304 cattle inspected and analyzed, only 7 cattle $(0.54 \%)$ were positive for dicrocoeliasis with the presence of the parasite and eggs.

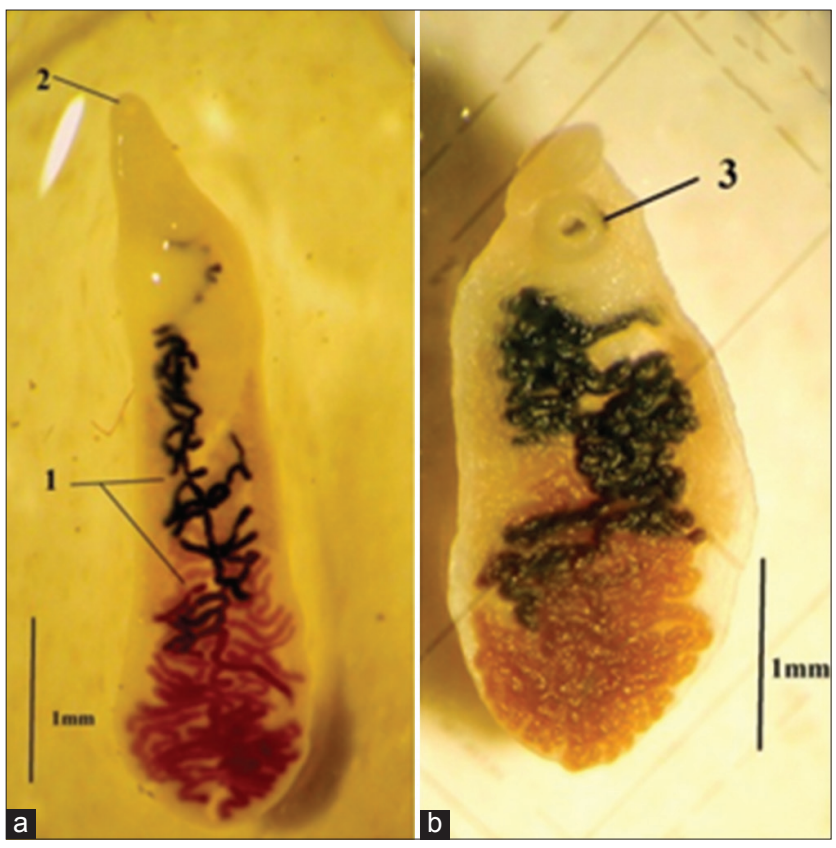

Figure-2: Adult Dicrocoelium dendriticum observed under a magnifying glass: (a) Adult parasite elongated form; (b) Adult parasite squat form (2: Oral sucker, 1: Uterus, and 3: Ventral sucker) with a translucent body.
Whereas Bejaia Province has the lowest prevalence among the 1091 cattle inspected and analyzed; only 3 cattle $(0.27 \%)$ were positive for dicrocoeliasis with the presence of eggs and adults of the parasite (Table-1).

\section{Association between dicrocoeliasis and sex, age, and season}

The risk factors (age, sex, and season) are the same for the three districts (Tizi-Ouzou, Bouira, and Bejaia); therefore, the entire cattle herd in the three districts was selected for the statistical study.

\section{Season}

Among $0.52 \%$ of positive cases, $0.15 \%$ were identified in summer, $0.12 \%$ in autumn, and $0.22 \%$ in spring, compared to a prevalence of $0.02 \%$ in winter. No significant association between the positivity of $D$. dendriticum and season was observed ( $\mathrm{p}>0.05)$ (Table-2).

Age

Of the $0.52 \%$ of positive cases, $0.25 \%$ were aged ( $>4$ years), $0.22 \%$ were middle-aged ( $2-4$ years), and $0.05 \%$ were young $(<2$ years). There is a significant association between the positivity of the animal to D. dendriticum and the age class $(\mathrm{p}<0.05)($ Table-2).

$\operatorname{Sex}$

Of the $0.52 \%$ of positive cases, $0.37 \%$ were female and $0.15 \%$ were male. There is a significant difference according to the animal's sex (male or female) for $D$. dendriticum $(\mathrm{p}<0.05)$ (Table-2).

\section{Morphological measurements}

Table-3 presents the results of the morphological measurements. Flukes' body was flattened, translucent lanceolate, narrower in the anterior region than in the posterior region. The average body length was $3.69 \mathrm{~mm}$ and the maximum average body width was $1 \mathrm{~mm}$ at the vitelline glands $(\mathrm{Vg})$ or in the posterior part of the body. Its integument is smooth (Teg) (Figure-4d).

The oral sucker (Os) was round and located at the anterior end of the body (Figure- $4 \mathrm{~b}$ ). The mean

Table-1: Summary of different diagnostic techniques in the three districts (Bouira, Tizi-Ouzou, and Béjaia).

\begin{tabular}{|c|c|c|c|c|}
\hline \multirow[t]{2}{*}{ Pathological } & \multicolumn{4}{|c|}{ Wilayas } \\
\hline & Bejaia n (\%) & Tizi-Ouzou n (\%) & Bouira n (\%) & Total n (\%) \\
\hline \multicolumn{5}{|l|}{ Bile analysis } \\
\hline$+^{c}$ & $3(0.27)$ & $11(0.66)$ & $7(0.54)$ & $21(0.52)$ \\
\hline$-d$ & $1088(99.7)$ & $1647(99.3)$ & $1297(99.4)$ & $4032(99.48)$ \\
\hline \multicolumn{5}{|c|}{ Coproscopic analysis } \\
\hline$+^{\mathrm{c}}$ & $2(0.18)$ & $5(0.3)$ & $3(0.23)$ & $10(0.25)$ \\
\hline$-d$ & $1089(99.8)$ & 1653 (99.7) & 1301 (99.7) & $4043(99.75)$ \\
\hline \multicolumn{5}{|l|}{ Liver inspection } \\
\hline Chol+dist $+^{a}$ & $3(0.27)$ & $11(0.66)$ & $7(0.54)$ & $21(0.52)$ \\
\hline Chol+dist- ${ }^{b}$ & $167(15.3)$ & $312(18.8)$ & $130(9.96)$ & $609(15)$ \\
\hline Healthy & $921(84.4)$ & 1335 (80.5) & 1167 (89.5) & $3423(84.46)$ \\
\hline
\end{tabular}

${ }^{a}$ Chol+dist+=Distomian cholangitis (inflammation of the bile ducts with the presence of the parasite),

${ }^{\mathrm{b}} \mathrm{Chol}+$ dist $-=$ Non-distomian cholangitis (inflammation of the bile ducts without the presence of the parasite),

${ }^{c}(+)=$ Presence of eggs of Dicrocoelium dendriticum, ${ }^{\mathrm{d}}(-)=$ Absence of eggs of $D$. dendriticum 
Table-2: Summary of positive cases according to risk factors (seasons, sex, and age).

\begin{tabular}{lcc}
\hline Risk factors & \multicolumn{2}{c}{ Infection } \\
\cline { 2 - 3 } & $\mathbf{+ ( \% )}$ & $\mathbf{- ( \% )}$ \\
\hline Seasons & $5(0.12)$ & $1034(25.5)$ \\
$\quad$ Autumn & $1(0.025)$ & $1003(24.74)$ \\
Winter & $9(0.22)$ & $1016(25.1)$ \\
Spring & $6(0.15)$ & $979(24.15)$ \\
$\quad$ Summer & $6(0.15)$ & $3534(87.2)$ \\
Sex & $15(0.37)$ & $498(12.3)$ \\
$\quad$ Male & & \\
Female & $10(0.25)$ & $319(7.87)$ \\
Age (years) & $9(0.22)$ & $1090(26.9)$ \\
$\quad$ Aged $(>4)$ & $2(0.05)$ & $2623(64.7)$ \\
$\quad$ Intermediate (2-4) & \\
$\quad$ Young $(<2)$ &
\end{tabular}

Table-3: Morphometric data of Dicrocoelium dendriticum (from cattle).

\begin{tabular}{|c|c|c|c|}
\hline \multirow[t]{2}{*}{$\begin{array}{l}\text { Body/ } \\
\text { organs }\end{array}$} & \multirow[t]{2}{*}{ Items } & \multicolumn{2}{|c|}{$\begin{array}{c}\text { Dicrocoelium } \\
\text { dendriticum }(\mu \mathrm{m})\end{array}$} \\
\hline & & Minimum-Maximum & Mean \\
\hline \multirow[t]{2}{*}{ Body } & Length & $2600-4600$ & 3690 \\
\hline & Width & $1000-1200$ & 1000 \\
\hline \multirow[t]{2}{*}{ Oral sucker } & $\begin{array}{l}\text { Diameter } \\
\text { internal }\end{array}$ & 90-111 & 103.66 \\
\hline & External & $245-285$ & 271.76 \\
\hline \multirow{2}{*}{ Ventral sucker } & Diameter & $102-120$ & 113.19 \\
\hline & $\begin{array}{l}\text { internal } \\
\text { External }\end{array}$ & $312-366$ & 344 \\
\hline \multirow[t]{2}{*}{ Testes } & Length & $250-300$ & 272.14 \\
\hline & Width & $480-580$ & 537.42 \\
\hline \multirow[t]{2}{*}{ Ovary } & Length & $90-115$ & 107 \\
\hline & Width & $180-285$ & 230 \\
\hline $\begin{array}{l}\text { Vitelline } \\
\text { glands }\end{array}$ & Length & $855-1500$ & 1107.71 \\
\hline \multirow{2}{*}{$\begin{array}{l}\text { Eggs in the } \\
\text { uterus }\end{array}$} & Length & $31.6-38.8$ & 34.19 \\
\hline & Width & $20.8-25.6$ & 22.44 \\
\hline \multirow[t]{2}{*}{ Cirrus pouch } & Length & $420-450$ & 439 \\
\hline & Width & $120-140$ & 135.04 \\
\hline \multirow[t]{2}{*}{ Ootype } & Length & $60.2-67.9$ & 65.5 \\
\hline & Width & $102-111$ & 105.9 \\
\hline
\end{tabular}

external diameter of the buccal sucker was 271 $\mu \mathrm{m}$. Under the buccal sucker, a small round pharynx $(\mathrm{Ph})(60 \mu \mathrm{m})$ followed by a fine esophagus was observed (Figure-4d). The ventral sucker (Vs) was round and the mean external diameter was $344 \mu \mathrm{m}$ (Figure-4c).

The two globular testicles (T) were located immediately after the Vs, are arranged in slightly oblique tandem orientation so that their size varied from 250 to $300 \mu \mathrm{m}$ for length and 480 to $580 \mu \mathrm{m}$ for width (Figure-4a-d). The posture of the cirrus pouch $(\mathrm{Cp})$ was voluminous and elongated axial $(420-450 \mu \mathrm{m})$ (Figure-4e). Figure-4 also shows that the smallest ovary $(\mathrm{Ov})$ was located directly behind the testicle and that the ootype (Ot), measuring 60.2-67.9 $\mu \mathrm{m}$ long, was located at the bottom of the ovary (Figure-4a).

The Vg $(855-1500 \mu \mathrm{m})$ occupied $1 / 3$ of the parasite body in a central position and did not reach the posterior edge of the ovary (Figure-4c). The uterus (U)

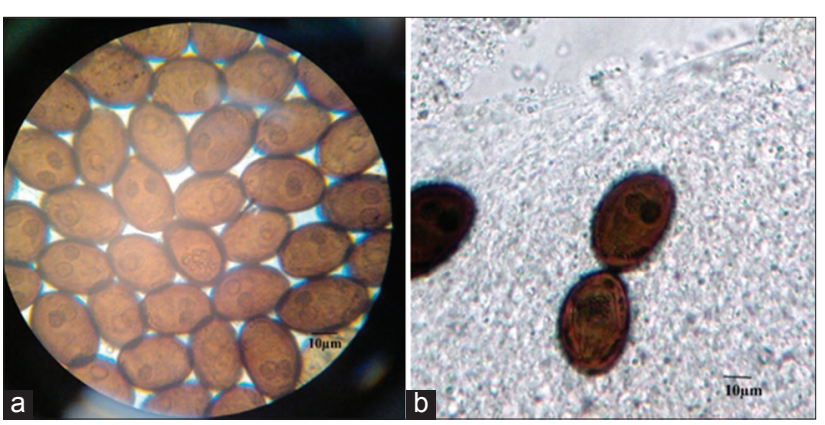

Figure-3: Numerous eggs of Dicrocoelium dendriticum in bile and stools observed under an optical microscope (Gr. 1000×). (a): Parasite eggs in the bile, (b): Parasite eggs in the stool (the egg is globally ellipsoid (asymmetrical), dark brown in color and capped).

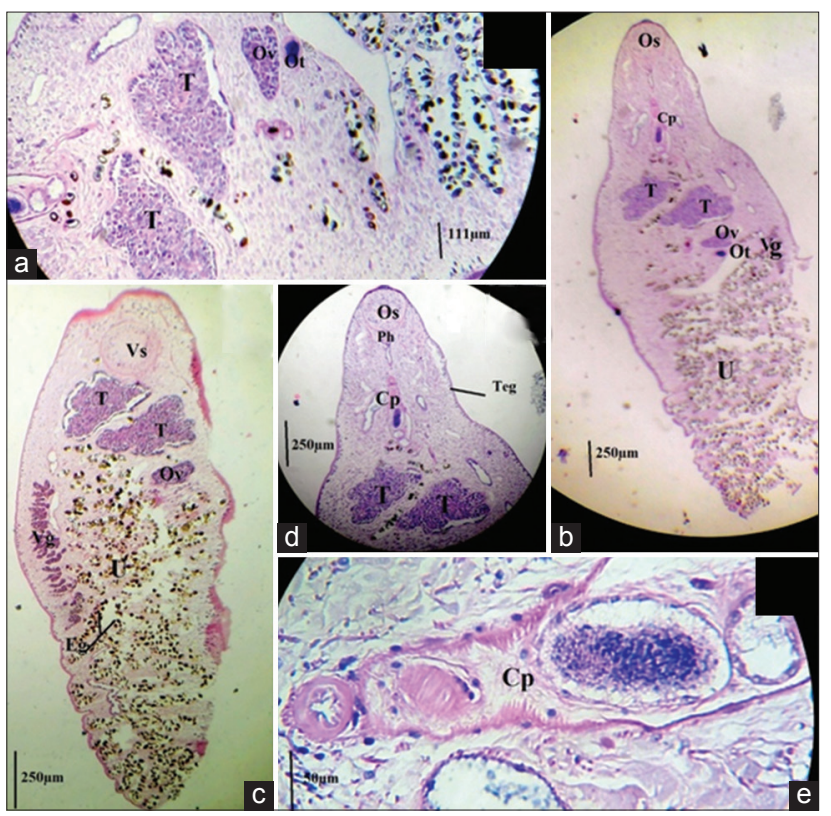

Figure-4: Histological section of an adult of Dicrocoelium dendriticum: (a) Histological section of the middle part of the parasite; (b) Complete histological section of the parasite "dorsal face;" (c) Complete histological section of the parasite "ventral face;" (d) Histological section of the anterior parasite; (e) Histological section of the cirrus pouch. (Cp: Cirrus pouch, Os: Oral sucker, Vs: Ventral sucker, T: Testes, Ov: Ovary, Ot: Ootype, Ph: Pharynx, $\mathrm{U}$ : Uterus filled with brown eggs of parasites (Eg), Teg: Its tegument is smooth).

occupied the posterior $2 / 3$ of Dicrocoelium spp. body, characterized by numerous convolutions (Figure-4c).

The eggs (Eg) were ellipsoidal, slightly asymmetric, measuring 31.6-38.8 $\mu \mathrm{m}$ long and 20.8-25.6 $\mu \mathrm{m}$ wide. They occupied the entire part of the uterus with a very light brown color in the posterior part of the parasite. In the anterior part, they were very dark brown and mature with a small operculum on one pole and surrounding two lighter vesicles on the opposite pole (Figure-4c).

\section{Discussion}

During this study, D. dendriticum was found for the $1^{\text {st }}$ time in some slaughterhouses in the Northern 
Province of Algeria, namely Bejaia, Tizi-Ouzou, and Bouira with a prevalence of $0.27 \%, 0.66 \%$, and $0.54 \%$, respectively, for a total prevalence of $0.52 \%$. The results are consistent with those obtained by many authors with dicrocoeliasis prevalences increasing from $1.47,1.76$, and $2.10 \%$ in $1999-2000$ to 0.69 , 0.34 , and $0.25 \%$ in $2003-2004$ in cattle, sheep, and goats successively [20].

In addition, $1,0.8$, and $1 \%$ of livers seized due to $D$. dendriticum in sheep, goats, and cattle, respectively, were reported in Western Iran [21]. In Arak, Iran, Arbabi et al. [22] indicated a prevalence of $0.77 \%$ in cattle, goats, and sheep. While in the Mitidja region of Algeria, a prevalence of $0.07 \%$ and $0.86 \%$ in cattle was recorded, corresponding, respectively, to flukes and eggs positive cases [12].

Other authors have noted higher prevalences, notably Schweizer et al. [23], with $47.2 \%$ of cases of dicrocoeliasis in Swiss farm cattle; Jithendran and Bhat [24] found $8.1 \%$ of sheep and $4.1 \%$ of goats positive for dicrocoeliasis in India; in Northern Niger, the prevalence of dicrocoeliasis was $56 \%$ in cattle, $13.1 \%$ for sheep, and $5.2 \%$ for goats [25]. Asanji and Williams [26] reported that $61.8 \%$ of cases of in cattle in Sierra Leone; Aminzare et al. [27] found that $5.95 \%$ of livers of sheep and goats slaughtered at the Nishapour slaughterhouse were condemned.

Coproscopic analysis detected the presence of $D$. dendriticum eggs in only 10 cattle, a prevalence of $0.25 \%$. These results are comparable to those obtained by Levasseur [28] who showed a low fecal excretion of Dicrocoelium eggs in cattle, with a number of PGOs ranging from 0 to 250, and an average close to 15 , which very often makes the diagnosis false negative.

Other authors reported higher prevalences. In Italy, Cringoli et al. [29], according to a coprological study of 81 cattle and 197 sheep farms, reported that $53.1 \%$ of cattle farms (43 of 81 farms) were positive for Dicrocoelium (16\% of animals) and 133 of 197 sheep farms $(67.5 \%)$ were positive for $D$. dendriticum. Bihaqi et al. [30] also noted a prevalence of $3.44 \%$ of Dicrocoelium spp. in goats in India based on a coprological study.

\section{Association between dicrocoeliasis and sex, age, and season}

The statistical analysis revealed no significant association between dicrocoeliasis and season $(\mathrm{p}>0.05)$, with a higher prevalence in spring $(0.22 \%)$, followed by summer $(0.15 \%)$, autumn $(0.12 \%)$, and finally winter $(0.025 \%)$.

The results are comparable to those obtained by Arbabi et al. [22] who reported no significant association between dicrocoeliasis and the season of the year. However, other authors have reported results with a significant association between season and dicrocoeliasis in sheep, cattle, and goats in Western Iran $(p<0.001)$. Hepatic condemnations due to dicrocoeliasis were frequent in autumn for sheep and cattle and in winter for goats [21].
This difference with the results of the present study may be caused by different environmental conditions. Iran is generally an arid country, but the west and north are rainier than the east and south. While Northern Algeria has a Mediterranean climate, summers are hot and dry and winters are warm and rainy and sometimes snowy.

On the other hand, the results also showed a significant association between dicrocoeliasis and sex, age of animal $(p<0.05)$; of $513(12.6 \%)$ females, $15(0.37 \%)$ were positive and of $3540(87.3 \%)$ males, only $6(0.15 \%)$ were positive, so females seem much more vulnerable to this disease.

This could be due, on the one hand, to their longer lifespan than males, which makes them more exposed to meadow and disease development, their physiology (gestation and lactation) leading to a reduction in immunity and more sensitive to parasitic diseases.

On the other hand, the female breeding methods used by farmers in Tizi-Ouzou, Bouira, and Bejaia Provinces are often extensive. Females tend to graze and therefore to be more exposed and infested, unlike males, whose breeding is often intensive because they are intended for fattening. In addition, the nature of their diet often consists of cereals in seed or ground, which exposes them to a lower risk of infestation.

With regard to the age factor, there seems to be a direct link with the sex factor, as males are slaughtered at a younger age, unlike females whose slaughter before 5 years is prohibited, except in the case of emergency and stamping out. The results obtained are comparable to those of Bihaqi et al. [30] who reported a higher incidence of gastrointestinal helminths among females than among males.

Dicrocoeliasis affecting cattle causes economic losses due to decreased milk production, reduced carcass weight, possible sterility, infertility, and finally seizure of parasitized livers at the slaughterhouse [8].

Histological analysis of Dicrocoelium shows that the flukes collected in Algeria are $D$. dendriticum of the anterior positioning of the testicles in tandem or slightly oblique unlike $D$. chinensis, which are in bilateral position [16], and the maximum width of the body is in the middle or in the posture of the body.

The parasite body is flat and translucent revealing all organs. The results show shorter parasite sizes ranging from 2.8 to $4.5 \mathrm{~mm}$, which differs from the more elongated Dicrocoelium hospes [17].

\section{Conclusion}

This work aimed to determine the presence or absence of $D$. dendriticum never reported before in Algeria. The results revealed the presence of D. dendriticum in three districts: Tizi-Ouzou, Bejaia, and Bouira. Its low prevalence confirms the beginning of the introduction of the parasite in Algeria, which could increase in the coming years if no measures are taken. 
The province of Tizi-Ouzou has the highest rate of infested cattle followed by Bouira and finally Bejaia. In addition, the results show that females and older animals are more likely to be affected by dicrocoeliasis. Animals with several years of grazing are more likely to excrete $D$. dendriticum eggs than those in the $1^{\text {st }}$ year of grazing.

Many studies on dicrocoeliasis among different bovine, sheep, and goat species must be carried out in Algeria both on its prevalence and its epidemiology. In particular, molecular identification of the small fluke would be useful to determine the presence of intraspecific variation of the species present in Algeria.

\section{Authors' Contributions}

$\mathrm{LC}$ and $\mathrm{KH}$ carried out the inspection of cattle livers in the different slaughterhouses, LC collected the samples (stools and bile) and performed the experiments. LC and MA realized the coprological and bile analysis; LC performed the histological analysis and analyzed the data. LC drafted the manuscript. All authors read and approved the final manuscript.

\section{Acknowledgments}

We would like to thank the veterinarians and workers at the different slaughterhouses for their precious help during the study. This work was financially supported by the Laboratory Research Animal Health and Production, Superior National Veterinary School, Algiers, Algeria.

\section{Competing Interests} interests.

The authors declare that they have no competing

\section{Publisher's Note}

Veterinary World remains neutral with regard to jurisdictional claims in published map and institutional affiliation.

\section{References}

1. Khanjari, A., Bahonar, A., Fallah, S., Bagheri, M., Alizadeh, A., Fallah, M. and Khanjari, Z. (2014) Prevalence of fasciolosis and dicrocoeliasis in slaughtered sheep and goats in Amol abattoir, Mazandaran, Northern Iran. Asian Pac. J. Trop. Dis., 4(2): 120-124.

2. Kantzoura, V., Kouam, M.K., Feidas, H., Teofanova, D. and Theodoropoulos, G. (2011) Geographic distribution modelling for ruminant liver flukes (Fasciola hepatica) in SouthEastern Europe. Int. J. Parasitol., 41(7): 747-753.

3. Shinggu, P.A., Olufemi, O.T., Nwuku, J.A., Baba-Onoja, E.B.T. and Iyawa, P.D. (2019) Liver flukes egg infection and associated risk factors in white fulani cattle slaughtered in Wukari, Southern Taraba State, Nigeria. Adv. Prev. Med., 2019: 2671620.

4. Otranto, D. and Traversa, D. (2002) A review of dicrocoeliasis of ruminants including recent advances in the diagnosis and treatment. Vet. Parasitol., 107(4): 317-335.

5. Jeandron, A., Rinaldi, L., Abdyldaieva, G., Usubalieva, J., Steinmann, P., Cringoli, G. and Utzinger, J. (2011) Human infections with Dicrocoelium dendriticum in Kyrgyzstan: The tip of the iceberg. J. Parasitol., 97(6): 1170-1172.

6. Beck, M.A., Goater, C.P. and Colwell, D.D. (2015) Comparative recruitment, morphology and reproduction of a generalist trematode, Dicrocoelium dendriticum, in three species of host. Parasitology, 142(10): 1297-1305.

7. Ofori, M., Bogoch, I.I. and Ephraim, R.K. (2015) Prevalence of Dicrocoelium dendriticum ova in Ghanaian school children. J. Trop. Pediatr., 61(3): 229-230.

8. Duchacek, L. and Lamka, J. (2003) Dicrocoeliasis the present state of knowledge with respect to wildlife species. Acta Vet. Brno, 72(4): 613-626.

9. Naeemipour, M., Hashemitabar, G.R., Dastjerdi, K., Mojaver, M.J. and Mohammadi, H.R. (2016) Comparison of fecal egg counts and ELISA for the diagnosis of Dicrocoelium dendriticum. Pol. J. Vet. Sci., 19(3): 573-580.

10. Mas-Coma, S., Rodriguez, A., Bargues, M.D., Valero, M.A., Coello, J.R. and Angles, R. (1997) Secondary reservoir role of domestic animals other than sheep and cattle in fascioliasis transmission in the Northern Bolivian altiplano. Res. Rev. Parasitol., 57(1): 39-46.

11. Gürelli, G. (2017) Importance of land snails in dicrocoeliasis epidemiology. Turk. Parazitol. Derg., 41(3): 169-172.

12. Chaouadi, M., Harhoura, K., Aissi, M., Boutellis, A. and Tazerouti, F. (2018) First abattoir report on bovine dicrocoeliasis from Algiers (Algeria). Veterinaria, 67(3): 145-147.

13. Yamaguti, S. (1971) Synopsis of Digenetic Trematodes of Vertebrates. Keigaku. Publishing. Ltd., Tokyo. p1073.

14. Hinaidy, H.K. (1983) Dicrocoelium suppereri nomen novum (syn. D. orientalis Sudarikov et Ryjikov 1951), a new trematode for the parasite fauna of Austria. Zentralbl. Veterinarmed. B, 30(8): 576-589.

15. Taira, K., Shirasaka, S., Taira, N., Ando, Y. and Adachi, Y. (2006) Morphometry on lancet flukes found in Japanese sika deer (Cervus nippon centralis) captured in Iwate prefecture, Japan. J. Vet. Med. Sci., 68(4): 375-377.

16. Otranto, D., Rehbein, S., Weigl, S., Cantacessi, C., Parisi, A., Lia, R.P. and Olson, P.D. (2007) Morphological and molecular differentiation between Dicrocoelium dendriticum (Rudolphi, 1819) and Dicrocoelium chinensis (Sudarikov and Ryjikov, 1951) tang and tang, 1978 (Platyhelminthes: Digenea). Acta Trop., 104(2-3): 91-98.

17. Bourgat, R., Seguin, D. and Bayssade, D.C. (1975) Données nouvelles sur Dicrocoelium hospes Looss, 1907: Anatomie de l'adulte et cycle évolutif. Note préliminaire. Ann. Parasitol. Hum. Comp., 50(6): 701-713.

18. Dinnik, J.A. and Dinnik, N.N. (1963) A method for the simultaneous diagnosis of schistosomiasis, fascioliasis and paramphistomiasis in cattle. Bull. Epizoot. Dis. Afr., 11(1): 29-36.

19. Teuscher, E. (1965) A new single method of examining feces for the diagnosis of helminth diseases of ruminant. Zentralbl. Veterinärmed. B, 12(3): 241-248.

20. Ansari-Lari, M. and Moazzeni, M. (2006) A retrospective survey of liver fluke disease in livestock based on abattoir data in Shiraz, South of Iran. Prev. Vet. Med., 73(1): 93-96.

21. Shahbazi, Y., Hashemnia, M. and Safavi, E.A. (2016) A retrospective survey of liver flukes in livestock based on abattoir data in Kermanshah, West of Iran. J. Parasit. Dis., 40(3): 948-953.

22. Arbabi, M., Nezami, E., Hooshyar, H. and Delavari, M. (2018) Epidemiology and economic loss of fasciolosis and dicrocoeliasis in Arak, Iran. Vet. World, 11(12): 1648-1655.

23. Schweizer, G., Plebani, G.F. and Braun, U. (2003) Prevalence of Fasciola hepatica and Dicrocoelium dendriticum in the cow: Inspection in an East Switzerland abattoir. Schweiz. Arch. Tierheilkd., 145(4): 177-179.

24. Jithendran, K.P. and Bhat, T.K. (1996) Prevalence of dicrocoeliasis in sheep and goats in Himachal Pradesh, India. Vet. Parasitol., 61(3-4): 265-271.

25. van Veen, T.W.S., Folaranmi, D.O., Usman, S. and Ishaya, T. (1980) Incidence of liver fluke infections (Fasciola gigantica and Dicrocoelium hospes) in ruminants in Northern Nigeria. Trop. Anim. Health Prod., 12(2): 97-104.

26. Asanji, M.F. and Williams, M.O. (1984) The effect of sex on seasonal variation in single and double infection of 
cattle in Sierra Leone by Dicrocoelium hospes and Fasciola gigantic. Vet. Parasitol., 15(3-4): 247-255.

27. Aminzare, M., Hashemi, M., Faz, S.Y., Raeisi, M. and Hassanzadazar, H. (2018) Prevalence of liver flukes infections and hydatidosis in slaughtered sheep and goats in Nishapour, Khorasan Razavi, Iran. Vet. World, 11(2): 146-150.

28. Levasseur, G. (2002) La dicrocœliose bovine: Suivi de l'excrétion pendant l'hiver. Bull. GTV, 13: 137-139.
29. Cringoli, G., Rinaldi, L., Veneziano, V., Capelli, G. and Malone, J.B. (2002) A cross-sectional coprological survey of liver flukes in cattle and sheep from an area of the Southern Italian Apennines. Vet. Parasitol., 108(2): 137-143.

30. Bihaqi, S.J., Allaie, I.M., Banday, M.A.A., Wani, Z.A. and Shahardar, R.A. (2017) Prevalence of caprine GI helminths in temperate areas of Jammu and Kashmir. J. Parasit. Dis., 41(3): 843-849.

$* * * * * * * *$ 